\title{
Bilateral Advancement Heart-Shaped Anoplasty for Severe Anal Stenosis: A New technique
}

\author{
Ajay K. Khanna ${ }^{1, \odot ~ S o u m y a ~ K h a n n a ' ~}$ \\ ${ }^{1}$ Institute of Medical Sciences, Banaras Hindu University, Varanasi, \\ Uttar Pradesh, India
}

\begin{abstract}
Address for correspondence Ajay K. Khanna, MS, Institute of Medical Sciences, Banaras Hindu University, Varanasi 221005, Uttar Pradesh, India (e-mail: akhannabhu@gmail.com).
\end{abstract}

Int J Recent Surg Med Sci 2021;7:13-16.

\begin{abstract}
Keywords

- cicatrization

- scar

- anoplasty

- advancement

- hemorrhoidectomy

Severe anal stenosis is an unusual complication following hemorrhoidectomy but leads to severe morbidity. The treatment of severe anal stenosis is usually some type of anoplasty. We designed a heart-shaped bilateral advancement anoplasty for the correction of this condition. We carried out this operation in five patients with successful results.
\end{abstract}

\section{Introduction}

Anal stenosis, the narrowing of the anal canal if left untreated can lead to serious complications. It can be mild, moderate, and severe and it causes constipation, pseudodiarrhea, painful bowel movements, and rectal bleeding. Mild stenosis is managed conservatively, usually by stool softener. Further if needed, mild-to-moderate sphincterotomy may be carried out on an outpatient basis with the goal of relieving pressure on the sphincter muscles. But severe anal stenosis necessitates anoplasty. An anoplasty is a reconstructive surgery that involves replacing scarred anal canal lining with a more pliable tissue. When conservative managements fail, anoplasty is indicated. The principle of strictureplasty consists of increasing anal caliber and removal of cutaneous scarring by using different methods of advancement flaps. ${ }^{1}$ There are many corrective techniques in the literature, and the choice of the operation depends both from the surgeon's experience and severity of stricture.,3 We have carried out heart-shaped bilateral advancement anoplasty for five patients. We call it heart shaped as the final appearance of the flap looks like heart.

\section{Technique of Heart-Shaped Bilateral Advancement Anoplasty}

This technique is carried out in patient with severe anal stenosis following the hemorrhoidectomy done 3 years back in

published online Janvary 27, 2021
DOI https://doi.org/ 10.1055/s-0041-1723051 ISSN 2455-7420. a 40-year-old male patient. Before surgery, the patient underwent routine checkup and was found to be in good, healthy status with an ASA (American Society of Anaesthetist) score of 1. Preoperative antibiotics in form of cephalosporin and metronidazole was given. The patient was catheterized and was given spinal anesthesia. The patient was operated in jackknife position with buttocks strapped to the table ( - Fig. 1). A circumferential incision was made all around the cicatrized anus and all the scarred tissue was excised up to the healthy anal mucosa. After excision of scarred anus, the advancement flap was designed. On either side from 11 to 5 o'clock and another incision from 1 to 5 o'clock, incisions are made approximately $5 \mathrm{~cm}$ on either side of the anal mucosa (-Figs. 2-4). The flaps are deepened on the subcutaneous plane up to the muscles but without any cut on the muscles. The flaps are raised full thickness up to about $2.5 \mathrm{~cm}$ from anal mucosa. After proper hemostasis, the inner margin of the flap is sutured to the anal mucosa by $2 / 0$ Polyglactin (Vicryl) sutures in a continuous fashion on either side ( $\mathbf{- F i g s .} \mathbf{5}$ and $\mathbf{6}$ ). Then the subcutaneous fat of the flap on either side is sutured with continuous $3 / 0$ Polyglactin (Vicryl) and the skin is sutured by interrupted 3/0 Polypropylene (Prolene) sutures. Final appearance of the flap looks like a heart so it is called as heart-shaped bilateral advancement anoplasty (-Figs. 7-9).

The patient was managed postoperatively either in prone or lateral position for 24 to 48 hours. The patients are given antibiotics for 3 to 5 days along with analgesics as needed.

(c) 2021. Medical and Surgical Update Society.

This is an open access article published by Thieme under the terms of the Creative Commons Attribution-NonDerivative-NonCommercial-License, permitting copying and reproduction so long as the original work is given appropriate credit. Contents may not be used for commercial purposes, or adapted, remixed, transformed or built upon. (https://creativecommons.org/licenses/by-nc-nd/4.0/). Thieme Medical and Scientific Publishers Pvt. Ltd. A-12, 2nd Floor, Sector 2, Noida-201301 UP, India 


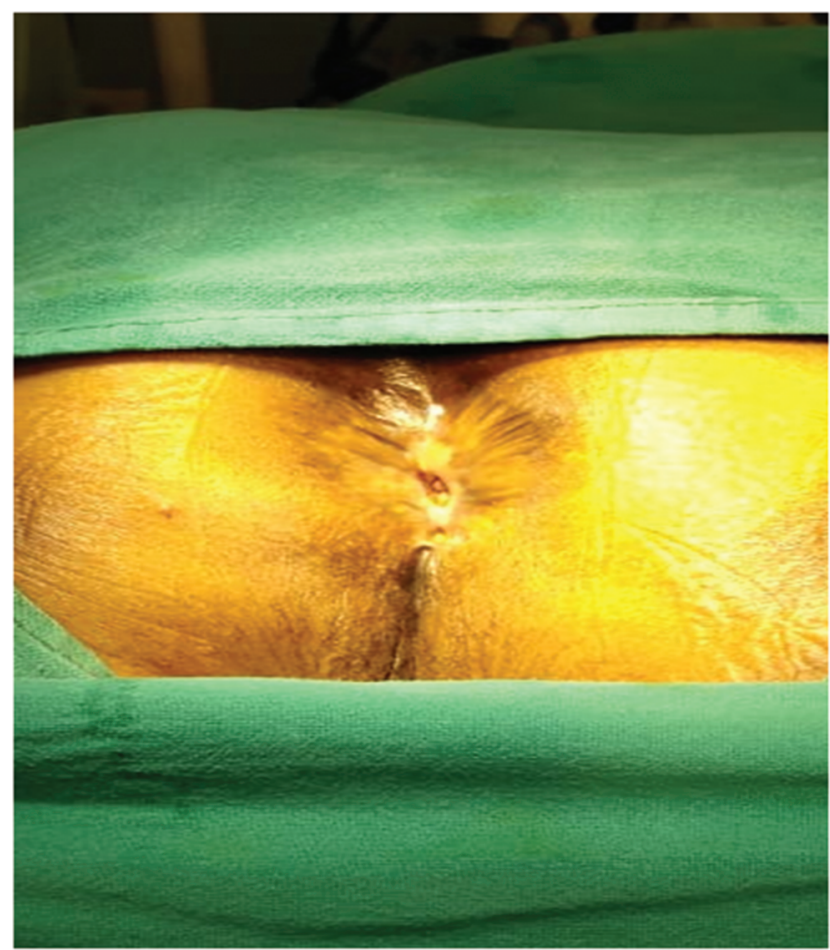

Fig. 1 Preoperative picture in jack-knife position.

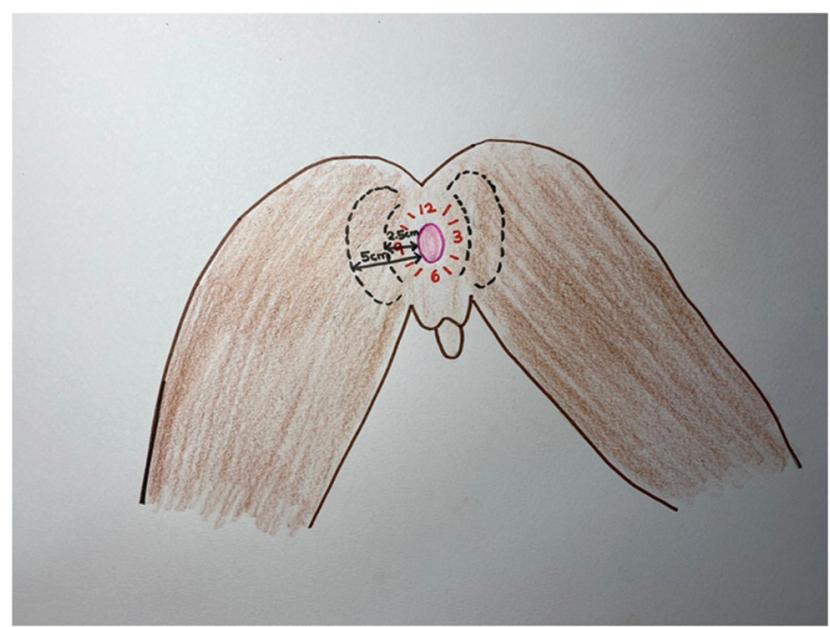

Fig. 2 . After circumferential excision of scarred anus, the bilateral flap was planned.

The catheter was removed after 24 to 48 hours. The patients were discharged at approximately 72 hours after surgery. The patients were called up for follow-up and sutures were removed at approximately 14 days ( $\mathbf{- F i g s . 8} 8$ and $\mathbf{9}$ ). The patients were advised to pass stool on commode. Usually no laxatives were required. Patients are followed up regularly to see for infection, bowel continence, etc.

This technique has been carried out in five patients and their demography is shown in - Table $\mathbf{1}$. There were three males and two females. All patient had history of hemorrhoidectomy in past and in two patients, there was history

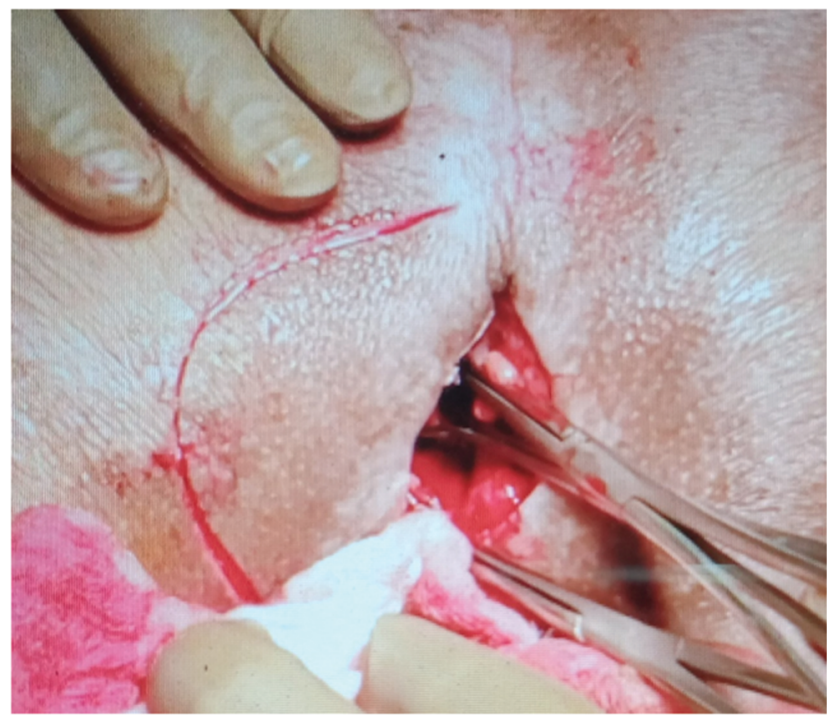

Fig. 3 After excision of scarred tissue, flap being planned on one side.

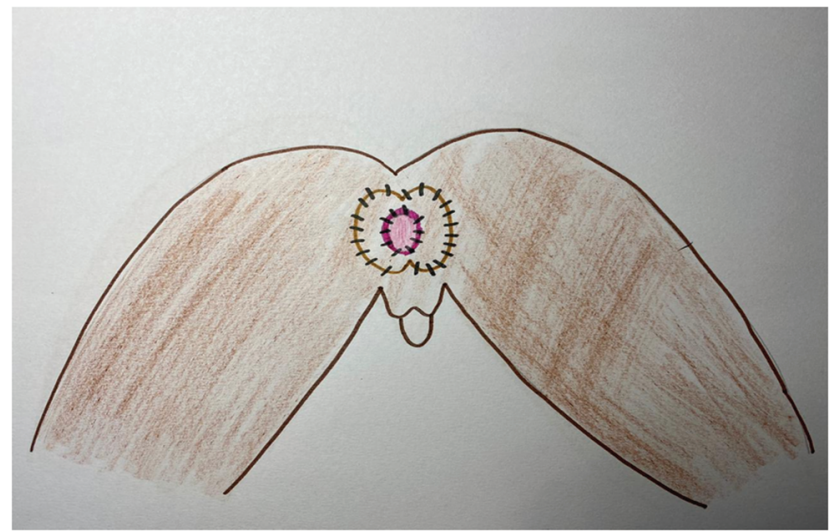

Fig. 4 After suturing the flap on both sides.

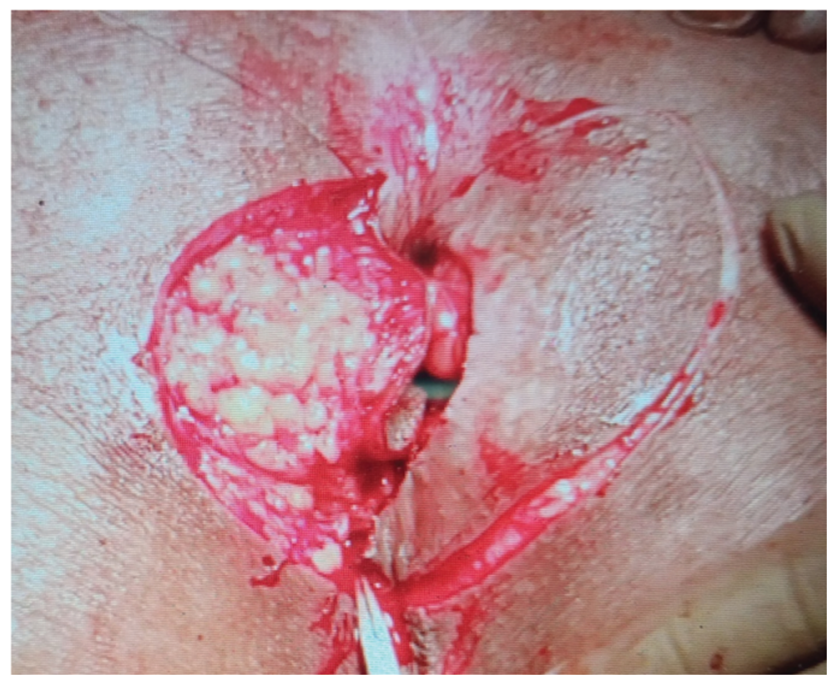

Fig. 5 Flap sutured on one side and flap planned on other side.

of chemical cauterization. All patients had severe anal stenosis 


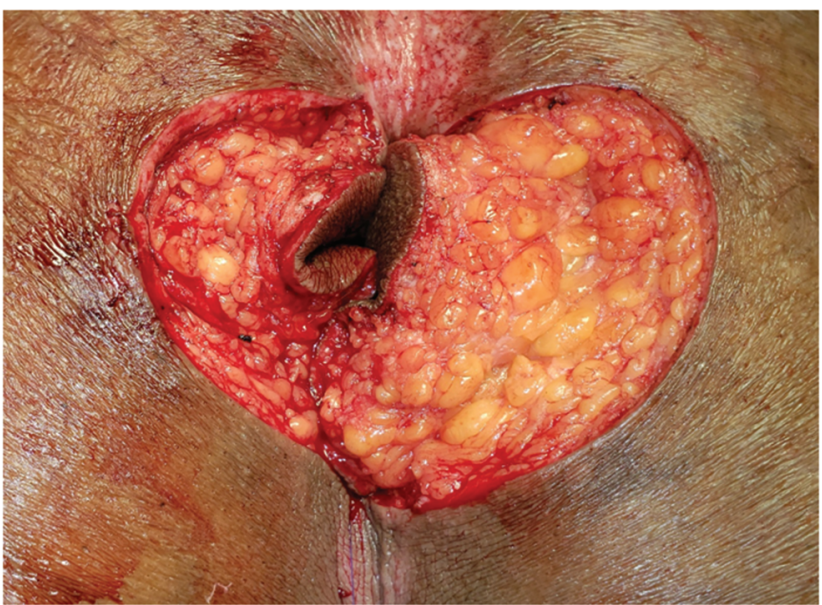

Fig. 6 Flap inner edges sutured to anal margins.

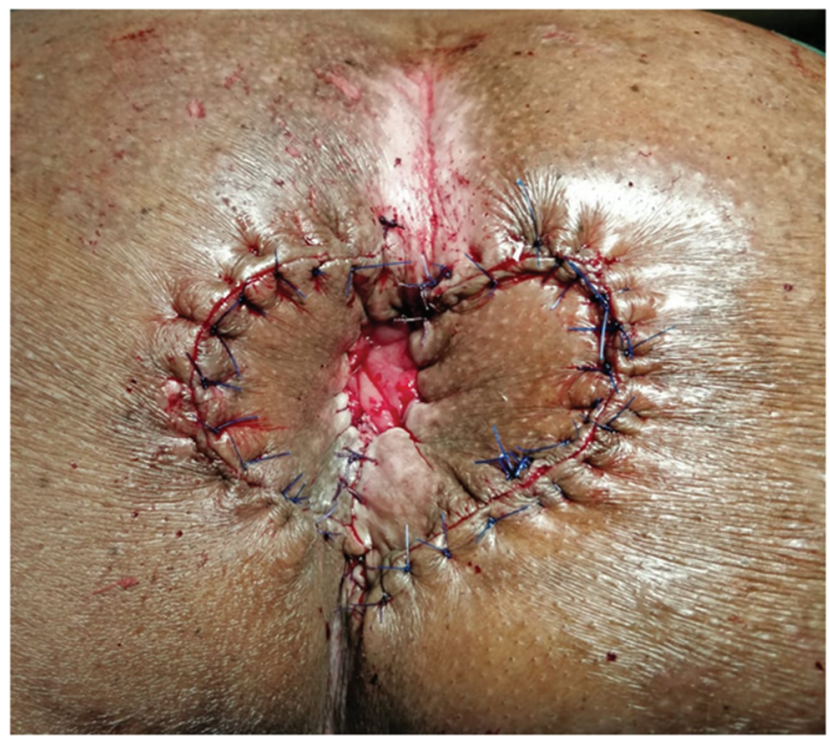

Fig. 7 Final appearance.

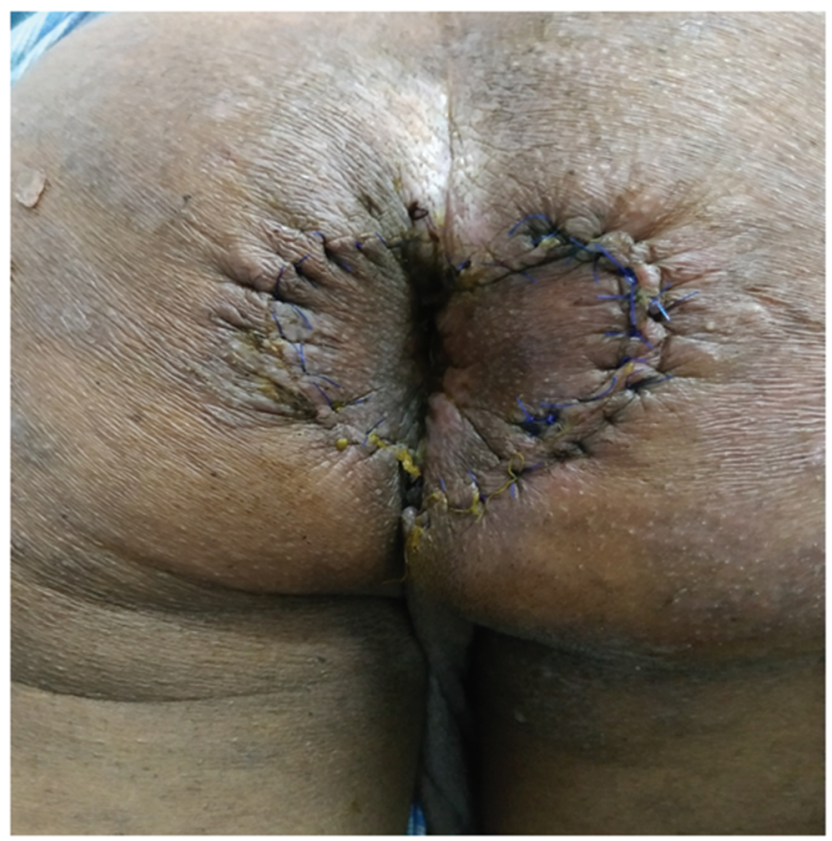

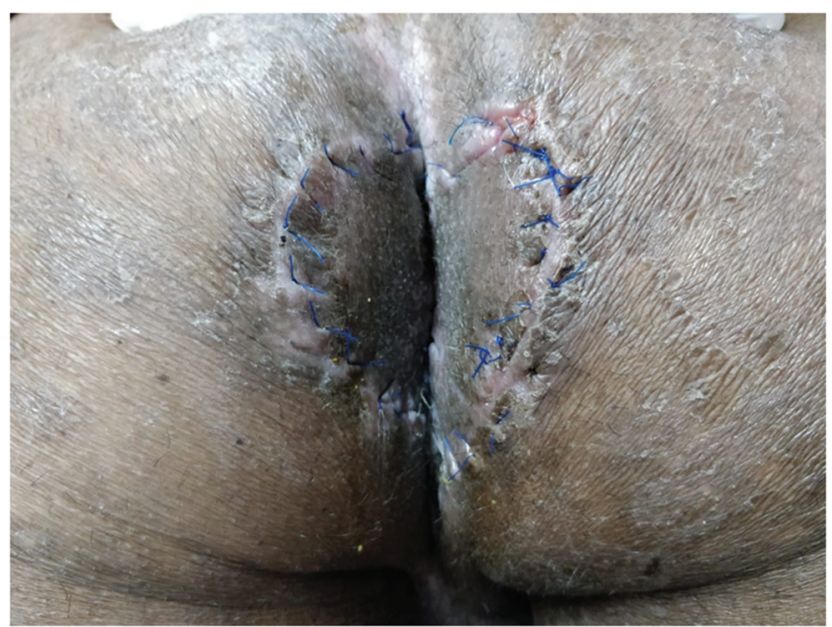

Fig. 9 Postoperative day 15.

Table 1 Demography

- No. of patients: 5

- Male:female = 3:2

- Age: 25-45 years

- Cause: posthemorrhoidectomy (two cases: chemical)

- Duration: 5-12 years

- Type of stenosis: severe

- Table 2 Complications

- Bleeding: nil

- Seroma: nil

- Hematoma: nil

- Infection: mild in one

- Flap necrosis: none

- Mucus discharge for initial period (approximately, 1-2 weeks): all

- Incontinence: none

- Restenosis: 1 (managed on self-anal dilatation)

We have followed our patients from 1 to 3 years with one patient having a mild restenosis which was managed by the patient by self-anal dilatation with laxatives. None of our patient was in continent after surgery.

The complications of the technique are shown in - Table 2. The most important problem in postoperative period is the mild mucus discharge which persisted for about 1 to 2 weeks and subsided on its own. One patient developed mild anal stenosis which was well managed by self-anal dilatation by the patient.

\section{Discussion}

The causes of anal stenosis can vary among anorectal surgery, inflammatory bowel disease (e.g., Crohn's disease), venereal disease, radiation therapy, and long-term laxative abuse. The main cause of anal stenosis is overzealous hemorrhoid operation. It can also be caused by application of local drugs. ${ }^{3}$

Anoplasty is a safe method with acceptable results in relieving the symptoms of anal stenosis. ${ }^{4}$ Planning of

Fig. 8 Postoperative day 7. 
treatment of anal stenosis depends on the severity. Milsom and Mazier ${ }^{5}$ classified the anal stenosis in three varieties: mild, moderate, and severe. The mild variety is when there is tight anal canal but it can be examined with well lubricated index finger, moderate variety can be examined by forceful dilatation to insert the index finger, and severe anal stenosis when the little finger cannot be inserted unless a forceful dilatation is employed. Further, stenosis may be ring like or annular or tubular. Depending on anal canal levels, stenosis may be low stenosis, middle, or high. ${ }^{5}$

No doubt, prevention is the best treatment of anal stenosis, especially after hemorrhoidectomy. Adequate preservation of mucocutaneous junction is the key preventing factor in avoiding anal stenosis. ${ }^{6}$ Further treatment will depend on the type of stenosis. Mild type can be managed by conservative measures but the severe type needs some type of anoplasty. A variety of anoplasty techniques has been described like lateral mucosal advancement flap, Y-V advancement flap, V-Y advancement flap, diamond-shaped flap, house flap, U flap, C flap, rotational S flap, internal pudendal flap, and foreskin anoplasty. ${ }^{7}$ All the techniques have their advantages and disadvantages and it all depends on the type of stenosis. The type of the flap to be used is based on the expertise of the surgeon in particular flap, as well as patient's anatomy and the availability of adequate perianal skin. Our heart-shaped bilateral advancement anoplasty is to be used for circumferential type of severe stenosis. The advantage of this flap is that both the flaps have adequate blood supply because of a very wide base, so there is no chance of flap necrosis, and because of the very wide flap, the chances of restenosis are very less. The only disadvantage we noticed was that there is slight ectropion of the anal mucosa in the initial period, so the patient may complain of mucus discharge, but this gets settled very fast in 1 or 2 weeks and then the patient remains well. We have followed-up our patients from 1 to 3 years with one patient having a mild restenosis which was managed by the patient by self-anal dilatation with laxatives. None of our patient was in continent after surgery.

\section{Conflict of Interest}

None declared.

\section{References}

1 Maria G, Brisinda G, Civello IM. Anoplasty for the treatment of anal stenosis. Am J Surg 1998;175(2):158-160

2 Tahamtan M, Ghahramani L, Khazraei H. Surgical management of anal stenosis: anoplasty with or without sphincterotomy. J Coloproctol (Rio J) 2017;37:13-17

3 Brisinda G. How to treat haemorrhoids. Prevention is best; haemorrhoidectomy needs skilled operators. BMJ 2000;321(7261):582-583

4 Acar T, Acar N, Tosun F, Ayaroğlu Ç, Haciyanli M. House advancement flap anoplasty for severe post-hemorrhoidectomy anal stenosis. Tech Coloproctol 2020;24(3):261-262

5 Milsom JW, Mazier WP. Classification and management of postsurgical anal stenosis. Surg Gynecol Obstet 1986;163(1):60-64

6 Khubchandani IT. Anal stenosis. Surg Clin North Am 1994;74(6):1353-1360

7 Brisinda G, Vanella S, Cadeddu F, et al. Surgical treatment of anal stenosis. World J Gastroenterol 2009;15(16):1921-1928 